\title{
Mechanistic understanding toward the toxicity of graphene-family materials to freshwater algae
}

Jian Zhao, ${ }^{\mathrm{a}}$ Xuesong Cao, ${ }^{\mathrm{a}}$ Zhenyu Wang, ${ }^{*, \mathrm{~b}, \mathrm{c}}$, Yanhui Dai, ${ }^{\mathrm{a}}$ and Baoshan Xing ${ }^{*, \mathrm{~d}}$

${ }^{a}$ College of Environmental Science and Engineering, and Ministry of Education Key Laboratory of Marine Environment and Ecology, Ocean University of China, Qingdao 266100, China

${ }^{\mathrm{b}}$ School of Environmental and Civil Engineering, Jiangnan University, Wuxi 214122, China

${ }^{\mathrm{c}}$ Laboratory for Marine Ecology and Environmental Science, Qingdao National Laboratory for Marine Science and Technology, Qingdao 266071, China

${ }^{\mathrm{d}}$ Stockbridge School of Agriculture, University of Massachusetts, Amherst, Massachusetts 01003 United States

*Corresponding authors

Tel.: +1 4135455212

E-mail address: bx@umass.edu (Dr. Baoshan Xing); wang0628@ouc.edu.cn (Dr. Zhenyu Wang) 


\section{Abstract}

We systematically investigated the toxicity mechanism of three graphene-family materials (GFMs), graphene oxide (GO), reduced graphene oxide (rGO) and multi-layer graphene (MG), to algae (Chlorella pyrenoidosa). GFMs exhibited much higher toxicity than other carbon materials (carbon nanotube and graphite), with the $96 \mathrm{~h}$ median effective concentration $\left(\mathrm{EC}_{50}\right)$ values of $37.3(\mathrm{GO}), 34.0(\mathrm{rGO})$, and 62.2 (MG) $\mathrm{mg} / \mathrm{L}$. Shading effect contributed approximately $16.4 \%$ of growth inhibition by GO due to its higher dispersibility and transformation while the other GFMs did not show any shading effect. Hydrophobic rGO and MG more readily heteroagglomerated with algae than GO, thus likely leading to more direct contacts with algae. Flow cytometry results showed significant decrease of membrane integrity after GFM exposure, and rGO caused the highest membrane damage, which was confirmed by the increased DNA and $\mathrm{K}^{+}$efflux. The observed membrane damage was caused by a combination of oxidative stress and physical penetration/extraction. Moreover, all the three GFMs could adsorb macronutrients $(\mathrm{N}, \mathrm{P}, \mathrm{Mg}$, and $\mathrm{Ca}$ ) from the algal medium, thus leading to nutrient depletion-induced indirect toxicity. GO showed the highest nutrient depletion (53\% of total toxicity) due to its abundant functional groups. The information provided in this work will be useful for understanding toxicity mechanism and environmental risk of different GFMs in aquatic environments.

Keywords: Graphene-family materials; Nanotoxicology; Heteroagglomeration; Membrane damage; Nutrient depletion 


\section{Introduction}

Graphene with a $\mathrm{sp}^{2}$-bonded carbon structure is a novel monolayer-thick carbon nanomaterial (Shen et al., 2014a; Zhao et al., 2014a). Graphene and its derivatives such as graphene oxide (GO) and reduced graphene oxide (rGO), are categorized as graphene-family materials (GFMs) (Zhao et al., 2014a). Owing to their excellent physiochemical properties, GFMs have been increasingly applied in various fields such as electronics, energy storage and biomedicine (Zurutuza and Marinelli, 2014; Novoselov et al., 2012). With increasing production and application (120 tons/year in 2015) (Zurutuza and Marinelli, 2014), GFMs will inevitably release into aquatic environments (Zhao et al., 2015a). Therefore, it is crucial to understand the aquatic toxicity of GFMs. It is reported that GFMs are toxic to bacteria, animals, plants and human cells (Liu et al., 2011; Fu et al., 2015; Zhao et al., 2015b; Hashemi et al., 2014). However, toxicological investigations of GFMs on algae are still limited. Algae, as a key primary producer, are generally recognized to be a more sensitive species to engineered nanoparticles (NPs) than other aquatic organisms such as bacteria, invertebrates and fish (Zhao et al., 2014a). Therefore, toxicological investigation of GFMs toward algae is essential to better understand their potential risk to aquatic ecosystems. Currently, all the existing toxicological data on algae are mainly focused on GO (Hu et al., 2014, 2015a). Other GFMs such as rGO, single-layered graphene (SG), and multi-layered graphene (MG) with different surface (e.g., O-containing groups) and structural properties (e.g., $\mathrm{sp}^{2} / \mathrm{sp}^{3}$ ratio) from GO are likely to exhibit different toxic effect to algae. It is reported that GO with better dispersibility caused 
higher membrane damage to E. coli than rGO (Liu et al., 2011). However, Akhavan and Ghaderi (2010) reported that $\mathrm{rGO}$ was a more toxic material to E. coli than GO due to sharper edges and better charge transfer. Therefore, it is hypothesized that surface (e.g., O-containing groups) and structural properties (e.g., $\mathrm{sp}^{2} / \mathrm{sp}^{3}$ ratio) of GFMs regulate their toxicity to algal cells through altering direct GFMs-algae contact (e.g., membrane damage) and indirect toxicity (e.g., shading effect and nutrient depletion).

Direct toxicity of GFMs is expected to initiate from direct GFM-algae interaction. During attachment of GFMs with algal cells, GFM-algae agglomeration and physical damage of algal membrane may occur. Li et al. (2013) observed edge or corner penetration of human cells membrane by graphene sheets through interacting with the tail groups of lipid molecules on bilayers. For algal cells, the major cell wall components are cellulose, glycoproteins and polysaccharides. Most algal cells could excrete extracellular polymeric substances (EPS) which are composed mainly of species-specific polysaccharides and proteins (Quigg et al., 2013). The surface and shape properties are expected to play important roles during the above GFM-algae attachment and possible penetration. Moreover, oxidative stress and other toxic mechanisms could be triggered during GFMs-algae interaction, which deserves investigation.

It should be noted that indirect nanotoxicity is likely to occur through reducing available light (shading effect) and depleting nutrients for algal growth, which has not been drawn attention in most nanotoxicological studies (Petersen et al., 2014). It is 
reported that multi-layered carbon nanotubes (MWCNTs) showed shading effect on algal growth (Long et al., 2012). For GFMs, shading effect could be caused by both GFMs suspending in aqueous phase and attaching with algal cells. GO and graphene with different hydrophilicity, dispersibility and light transmission property are expected to have different shading effect. In addition, GFMs possess high surface area and unique surface properties (e.g., abundant functional groups and surface charges), thus showing high adsorption capacity for both organic molecules and mineral ions (Zhao et al., 2014b; Sitko et al., 2013). Creighton et al. (2013) reported that GO indirectly inhibited the growth of human HepG2 cells by adsorbing the organic nutrients (folic acid) in the medium. However, there is only one study showing the nutrient depletion-induced toxicity, in which phytotoxicity was partly attributed to adsorbed macronutrients (K, N, P) and micronutrients (Fe, Mn, Zn) on negatively charged silica NPs (Slomberg and Schoenfisch, 2012). Algal medium is mainly composed of mineral nutrients. With much higher surface area than silica NPs, GFMs could adsorb much more mineral nutrients, and thus are hypothesized to induce significant nutrient depletion to inhibit algal growth.

Overall, we aimed to investigate the toxicity of three GFMs including GO, rGO, and MG to freshwater algae Chlorella pyrenoidesa based on their different physicochemical properties and colloidal behaviors. Direct toxicity (e.g., membrane damage) induced by GFMs-algae interaction and indirect toxicity including shading effect and nutrient depletion were explored in this present work. The contribution of individual potential mechanism was thus evaluated. The mechanistic investigation 
will be useful for understanding environmental risk of GFMs in aquatic environments.

\section{Materials and methods}

\subsection{Material preparation and characterization}

The preparation of GO followed the improved Hummers' method (Marcano et al., 2010). The detailed experimental procedure was in the Supporting Information (Experimental S1). rGO was obtained by reducing GO nanosheets with hydrazine hydrate $(35 \%)$ at $95{ }^{\circ} \mathrm{C}$ for $4 \mathrm{~h}$ (Hashemi et al., 2014). MG was purchased from Graphene Supermarket (USA). MWCNTs (Length: 5-15 $\mu \mathrm{m}$, diameter: 40-60 nm) (Shenzhen Nanotech Co., China) and graphite (Sinopharm Co., China) were used for comparison. The procedures for GFMs characterization using transmission electron microscopy (TEM, H-7650, Hitachi, Japan), atomic force microscopy (AFM, Agilent-5400, USA), x-ray diffraction (XRD, Bruker D8 Advance), Autosorb-1 (Quantachrome, USA), Fourier transform infrared spectroscopy (FTIR, Nicolet 6700, USA), Raman spectroscopy (Thermo Fisher, USA), elemental analyzer (MicroCube, Elementar, Germany), Zetasizer Nano (Nano Series ZS90, Malvern, Britain) are presented in the Supporting Information (Experimental S2). The algal growth inhibition assays are also shown in the Supporting Information (Experimental S3).

\subsection{Shading effect and agglomeration}

Effect of light shading by GFMs on algal growth inhibition was investigated following our pervious study (Wang et al., 2011). The experimental setup of shading effect is displayed in Figure S2. Briefly, 250-mL conical flasks with exponentially growing algal cells were placed into 1-L beakers which already contained GFM 
suspensions $(50 \mathrm{mg} / \mathrm{L})$ prepared in algal medium. The level of GFMs suspension in the beaker was kept in the same height with that of algal suspension in the conical flask. The algal cell numbers $\left(A_{1}\right)$ in the conical flasks were counted after shading in the GFMs suspension for $96 \mathrm{~h}$. A treatment with algal medium in the beaker was conducted as a control, and the algal cells $\left(A_{0}\right)$ in the conical flask were also counted after culturing for $96 \mathrm{~h}$. The contribution (\%) of shading effect on algal growth inhibition was then calculated as follows: $\left(A_{0}-A_{1}\right) / A_{0} * 100$.

The heteroagglomeration of algae with GFMs was investigated following the approach of Schwab et al. (2011) for CNTs. Briefly, the suspended algal cells and GFMs suspension (final concentration, $50 \mathrm{mg} / \mathrm{L}$ ) were mixed in $250-\mathrm{mL}$ flask. After settled down for $2 \mathrm{~h}$, algal cells in the aqueous phase were counted. Growth of algal cells was not significantly inhibited after inculcated with GFMs for $2 \mathrm{~h}$ (data not shown). Therefore, the reduction of algae number in aquatic phase after 2-h settling was attributed to their agglomeration with GFMs.

\subsection{Membrane integrity and leakage of intracellular substances after GFMs exposure}

Membrane integrity of algal cells after GFMs exposure was assessed using flow cytometry (BD Biosciences, San Jose, USA) (Zhao et al., 2013). Briefly, algal cells $\left(1 \times 10^{6}\right.$ cells $\left./ \mathrm{mL}\right)$ were treated with $50 \mathrm{mg} / \mathrm{L}$ GFMs (GO, rGO, or MG) for $96 \mathrm{~h}$. The collected algal cells were dyed with propidium iodide (PI, $50 \mathrm{mg} / \mathrm{L}$ ) for $20 \mathrm{~min}$ in dark. The fluorescence intensity (FI) of dyed algal cells was then determined by flow cytometry with a FL2 detector. Each sample was analyzed for at least 20,000 cells.

The measurement of electrolyte $\left(\mathrm{K}^{+}\right)$leakage from algal cells was determined 
following the approach in our previous study (Wang et al., 2012). The algal cells after GFMs exposure for $96 \mathrm{~h}$ were collected, and then washed with phosphate buffer solution (PBS) (0.1 M, pH 7.2) for three times. For each treatment, the washed algal cells were diluted with PBS $(0.1 \mathrm{M}, \mathrm{pH} 7.2)$ to the same algal cells density $\left(1 \times 10^{6}\right.$ cells $/ \mathrm{mL})$, and then shaken $(220 \mathrm{rpm})$ at $25{ }^{\circ} \mathrm{C}$ for $4 \mathrm{~h} . \mathrm{K}^{+}$content in algal medium was then determined by atomic absorption spectrophotometry (AAS, Thermo Solaar M6, USA).

The leakage of DNA from algal cells was also assessed (Kang et al., 2008). After exposure to GFMs for $96 \mathrm{~h}$, the cell suspension was centrifuged at 3,500 rpm for 10 min. The obtained supernatant was filtered through a $0.22 \mu \mathrm{m}$ membrane (low protein-binding, millex, Millipore Co.). The DNA fraction in the filtrate was then isolated using a DNA purification kit and measured with fluorescence spectroscopy (Hitachi F4600, Japan) using PI as a fluorescent dye (excitation 535 nm, emission 615 $\mathrm{nm})$.

\subsection{Oxidative stress- and physical penetration-induced membrane damage}

The generation of intracellular reactive oxygen species (ROS) was detected using an ROS indicator, $2^{\prime}, 7^{\prime}$-dichlorofluorescin diacetate ( $\mathrm{H}_{2}$ DCFDA) (Wang et al., 2011). The detailed procedure for ROS measurements is described in the Supporting Information (Experimental S4). Possible lipid peroxidation of algae induced by oxidative stress was also examined. The thiobarbituric acid reactive substance (TBARS, Sigma) was used to indicate malondialdehyde (MDA) content which reflects the lipid peroxidation level of algal cells after GFM exposure. MDA content 
of the algal cells after exposure to GFMs for $96 \mathrm{~h}$ was determined using Multiskan spectrum (Thermo, USA) at $532 \mathrm{~nm}$. The algal cells exposed to $200 \mu \mathrm{M}$ hydrogen peroxide for $2 \mathrm{~h}$ was set up as a positive control.

Direct GFMs-algae contact and possible physical damage of algal cells after GFMs exposure were observed with scanning electron microscopy (SEM). Briefly, algal cells pre-treated with GFMs (GO, rGO or MG) were prefixed in $2.5 \%$ glutaraldehyde for $12 \mathrm{~h}$, washed three times with phosphate buffer ( $\mathrm{pH} 7.2$ ), and then post-fixed in $1 \%$ osmium tetroxide for $2 \mathrm{~h}$. After fixation, all the samples were dehydrated with increasing concentrations of ethanol $(30,50,70,80,90,100 \%)$ and permeated with tert-butyl alcohol. Finally, these samples were freeze-dried and gold-coated, and then observed using SEM (HITACHI S-4800, Japan).

Interaction of GFMs with lipid bilayer of algal cells was further investigated using confocal laser scanning microscope (CLSM). The fluorescent dye DiI (1,1'-dioctadecyl-3,3,3',3'-tetramethylindocarbocyanine perchlorate) could specifically label the phospholipids in membrane. After treated with GFMs, cell membrane of algal cells was stained with $10 \mu \mathrm{M}$ DiI for $30 \mathrm{~min}$, and then visualized with CLSM (Olympus-FV1000, Japan). The wavelengths for excitation and emission were 549 and $565 \mathrm{~nm}$, respectively. Phosphatidylcholine (PC) was employed as a positive control to validate this approach. In addition, the FI of GFMs that were not dyed with DiI was also observed under the same wavelengths to exclude possible interference introduced by GFMs.

\subsection{Effect of nutrient adsorption by GFMs on algal growth}


To investigate nutrient depletion-induced indirect toxicity by GFMs, algal growth reduced by adsorption and removal of nutrients by GFMs from algal medium was conducted. Briefly, GFMs (GO, rGO or MG) were added to algal medium to reach the final concentration at $50 \mathrm{mg} / \mathrm{L}$, and then shaken under $25{ }^{\circ} \mathrm{C}$ for $96 \mathrm{~h}$. GFM suspensions were then centrifuged and filtered twice with $0.22 \mu \mathrm{m}$ membrane (millex, Millipore). The obtained supernatant and the algal medium without nutrient removal were used to culture algal cells, and the $96 \mathrm{~h}$ growth inhibition induced by nutrient depletion was then calculated. In addition, the concentrations of macroelements $(\mathrm{N}, \mathrm{P}$, $\mathrm{Ca}, \mathrm{Mg}, \mathrm{K})$ and microelements $(\mathrm{Fe}, \mathrm{Mn}, \mathrm{Cu}, \mathrm{Zn})$ in the supernatant were quantified. $\mathrm{K}$, $\mathrm{Ca}, \mathrm{Mg}, \mathrm{Fe}, \mathrm{Mn}, \mathrm{Cu}$, and $\mathrm{Zn}$ were detected using inductively coupled plasma mass spectrometry (ICP-MS, iCAP ${ }^{\mathrm{TM}} \mathrm{Q}$, Thermo Scientific, Germany). N and $\mathrm{P}$ were determined by UV-Vis spectroscopy following the approaches of Zhang et al. (2013) and Basta et al. (2014), respectively.

\subsection{Statistical analysis}

All the experiments were run at least three replicates. Statistical analysis of the data was performed using SPSS 16.0 by analysis of variance (ANOVA) with LSD method after the verification of normality and homoscedasticity assumption. We used $p<0.05$ for the statistical significance.

\section{Results and discussion}

\subsection{Characterization of GFMs}

The morphology showed the irregular folding of all the three GFMs (Figure S3). The lateral sizes of GO, rGO and MG were around 2, 1, and $2.5 \mu \mathrm{m}$, respectively. 
AFM images and related height profiles indicated that the thicknesses of GO, rGO, and MG were around 2.1, 1.5, and $5.0 \mathrm{~nm}$, respectively (Figure S4), which is positively correlated with their surface areas (Table 1). The Raman spectra of GFMs (Figure S5A) exhibited significant D band at approximately $1320 \mathrm{~cm}^{-1}$ and $\mathrm{G}$ band at approximately $1580 \mathrm{~cm}^{-1}$. The $\mathrm{D} / \mathrm{G}$ peak intensity ratio $\left(\mathrm{I}_{\mathrm{D}} / \mathrm{I}_{\mathrm{G}}\right)$ of $\mathrm{rGO}(1.04)$ was higher than GO (0.86), indicating the increased defects and/or edges of rGO after reduction (Akhavan, 2015). This can be supported by AFM imaging, in which obvious holes on the nanosheets of rGO were observed (Figure S4). MG with intact graphitic structure had the lowest $\mathrm{I}_{\mathrm{D}} / \mathrm{I}_{\mathrm{G}}(0.05)$. The interlayer spacing $(d)$ of $\mathrm{GO}$ was calculated to be $0.87 \mathrm{~nm}$ (Table 1, Figure S5B), which was much higher than that of rGO (0.37) and MG (0.34). This interlayer spacing increase was caused by the hydration and exfoliation of graphite flakes after oxidation (Zhao et al., 2015). Oxygen contents of GO and other GFMs were further analyzed (Table 1). GO had the highest oxygen percentages of $55.2 \%$, demonstrating the sufficient oxidization of GO nanosheets. FTIR spectra (Figure S5C) further showed that the O-containing groups such as $\mathrm{C}=\mathrm{O}$ and $\mathrm{C}-\mathrm{O}$ of $\mathrm{rGO}$ were much lower than $\mathrm{GO}$ due to the loss of oxygen after reduction as confirmed by the elemental compositional data (Table 1). For MG, the peaks of functional groups were not apparent due to the lowest oxygen content $(5.34 \%)$. Surface charges of the three GFMs in both distilled water and algal medium were positively related to their $\mathrm{O} / \mathrm{C}$ ratios and functionalities. Zeta potentials of GO, rGO, MG in algal medium $(-27.3,-24.7$, and $-19.6 \mathrm{mV})$ were less negative than those in distilled water $(-41.9,-32.7$, and $-25.6 \mathrm{mV})$, which can be explained by charge 
neutralization and compression of the electric double layer on GFMs by the inorganic ions in the algal medium.

\subsection{Toxicity of GFMs to algal cells}

The 96-h growth inhibition of algal cells highly depended on GFM concentrations (Figure 1A). The $\mathrm{EC}_{50}$ values of $\mathrm{GO}, \mathrm{rGO}, \mathrm{MG}, \mathrm{MWCNTs}$ and graphite were calculated as $37.3,34.0,62.2,137$, and $180 \mathrm{mg} / \mathrm{L}$, respectively. Clearly, GFMs were more toxic than MWCNTs and graphite. Toxicity of MWCNTs to algae has been addressed in previous studies (Long et al., 2012; Schwab et al., 2011; Kahru and Dubourguier, 2010). GFMs thus may be considered as a type of more toxic contaminant in the aquatic environment. Figure S6 shows the toxicity of GFMs (50 $\mathrm{mg} / \mathrm{L})$ as a function of exposure times $(24-96 \mathrm{~h})$. For all the materials, the growth inhibition highly increased with increasing exposure times (24-96 h) (Figure S6). At $24 \mathrm{~h}$, GO had the highest inhibition. However, rGO showed higher toxicity than GO with increasing exposure times. This exposure time-dependent toxicity is supported by a previous work (Liu et al. 2011), in which GO had higher bacterial inactivation rate than rGO during the first $2 \mathrm{~h}$ of incubation while the order was reversed with increasing incubation times. Liu et al. (2011) found that GO had higher toxicity and membrane damage of E. coli than rGO while the opposite order of the two GFMs was observed by Akhavan and Ghader (2010). This may be explained by the different colloidal behaviors of the employed GFMs. In our case, the toxicity of different GFMs was related to their different physicochemical properties and related colloidal behavior, which will be discussed below. 


\subsection{Shading effect and agglomeration of GFMs with algal cells}

Upon exposure, the dispersed NPs could reduce light transmittance of NPs suspension (Aruoja et al., 2009; Long et al., 2012). Indirect toxicity induced by shading effect of GFMs was thus investigated. Figure 1B shows that GO had significant shading effect on algal growth while other materials did not cause any reduction on algal growth through shading effect. GO shading caused $9.02 \%$ of the total growth inhibition (Figure S7) as calculated from the algal growth results (Figure 1B). The contribution of shading effect to the total GO toxicity (54.9\%, Figure S6) was then calculated as $16.4 \%$. The significant shading caused by GO is explained as follows: (1) GO was dispersed well during 96-h exposure due to its hydrophilic surface and strong electrostatic repulsion between individual GO sheets (zeta potential, $-27.3 \mathrm{mV}$ ), and (2) GO sheets became dark during incubation as shown in the insert image of Figure 1B, thus further reducing light availability for algal growth. The color change of GO after $96 \mathrm{~h}$ incubation demonstrated that GO was transformed, which can be induced by (i) light irradiation, and/or (ii) metabolites of algal cells. Hu et al. (2015b) reported that shading effect induced by GO resulted in growth inhibition of protozoa Euglena gracilis through reducing its photosynthesis, which is in agreement with our finding. Although suspensions of other carbon materials (e.g., rGO, MG and CNTs) were much darker, no significant shading effect was observed. The reason is that these carbon materials with strong hydrophobicity (as indicated by low oxygen percentage) and low surface charge (Table 1) could readily form big aggregates, thus settling down in aqueous phase (Figure S8). Schwab et al. (2011) reported that only 
the well-dispersed CNTs after oxidation or with the assistance of natural organic matter showed significant shading effect, which is consistent with our data.

When interacting with algal cells, GFMs may result in direct toxicity, GFM-algae heteroagglomeration was thus investigated. Figure $1 \mathrm{C}$ shows the number of suspended algae after settling for $2 \mathrm{~h}$ with GFMs. Around $45 \%$ and $43 \%$ of algal cells were co-settled with $\mathrm{rGO}$ and $\mathrm{MG}$, respectively, suggesting strong heteroagglomeration between algae and $\mathrm{rGO} / \mathrm{MG}$. The light microscope images clearly showed the attachment of algal cells on both rGO and MG sheets (Figure 1C). EPS is a multicomponent and amphiphilic biopolymer, with hydrophobic patches (e.g., proteins and other high-molecular-weight components) on the external surface of algae. It is reported that EPS on algal surface could strongly attach with nonfunctionalized and functionalized $\mathrm{CdSe}$ quantum dots due to hydrophobic and electrostatic interactions (Zhang et al., 2012). In our case, both rGO/MG (Table 1) and algal cells $(-20.24 \pm 0.97 \mathrm{mV})$ were negatively charged. Therefore, hydrophobic interaction, H-bonding, and cation bridging of metal ions (e.g., $\mathrm{Ca}^{2+}, \mathrm{Mg}^{2+}$ in the media) could be the main driving forces for heteroagglomeration between algae and rGO/MG by overcoming electrostatic repulsive force. For GO, insignificant algal sedimentation was observed after mixing with GO (Figure 1C). There are two possibilities for the observed insignificant sedimentation: (1) GO sheets were unable to attach on algal surface, or (2) GO sheets were attached on algal cells, but the GO-algae heteroaggregates could still suspend in the medium because of the high dispersibility of GO. We therefore designed another experiment to investigate the 
interaction between GFMs and algal cells (Figure S9A). One mL of algae suspension (left drop) and $1 \mathrm{~mL}$ of GFMs suspension $(50 \mathrm{mg} / \mathrm{L})$ (right drop) were placed on a culture plate and left there for 12 min. It is showed that around $40 \%$ of algal cells moved to the zones of rGO and MG suspensions while most of algal cells ( 90\%) still remained in the medium zone of GO (Figure S9B). The alga Chlorella pyrenoidosa has no flagellum and cannot move by itself. Therefore, the movement should be dominated through the attractive force between algae and $\mathrm{rGO} / \mathrm{MG}$. The algal movements caused by rGO and MG are highly consistent with the GFMs-algae heteroagglomeration results, indicating strong interaction between algae and rGO/MG. However, the interaction between GO and algae was weak as indicated by the insignificant change of algal number in the medium zone. SEM images showed that the attachment of GO (Figure S10B) on algal cells was much lower than that of rGO and MG (Figures S10C,S10D). All these findings suggested that the attachment of GO on algal cells were much weaker than rGO and MG. Strong electrostatic repulsion and low hydrophobic interaction between GO and algae were responsible for the weak GO-algae heteroagglomeration. Heteroagglomeration or contact between NPs and algae is an important factor for nanotoxicity. It was found that the heteroagglomeration with other NPs (e.g., CNTs and Ag NPs) contributed to the growth inhibition of algal cells (Zhang et al., 2016). Another study showed that the heteroagglomeration with CNTs accounted for approximately 60\% of algal growth inhibition (Long et al., 2012). Upon the attachment and physical interaction, membrane damage could be potentially penetrated and disrupted, thus causing direct 
toxicity to algal cells.

\subsection{Membrane damage of algal cells}

Membrane integrity of algal cells was investigated using flow cytometry. As shown in Figure 2A, 20,000 algal cells were distributed into two areas, and the green and red regions indicated the numbers of intact and membrane-damaged algal cells, respectively. GFMs-induced membrane damage followed the order of rGO $(23.0 \%)>$ MG $(14.9 \%)>$ GO $(9.2 \%)$. Intracellular matters would release after membrane break. Therefore the leakage of potassium ion $\left(\mathrm{K}^{+}\right)$and DNA was further examined. All the three GFMs significantly caused $\mathrm{K}^{+}$leakage, and extracellular $\mathrm{K}^{+}$contents followed rGO> MG> GO (Figure 2B), consistent with the flow cytometry results (Figure 2A). Similar to $\mathrm{K}^{+}$, DNA leakage from algal cells caused by rGO was also the highest in comparison with GO and MG (Figure 2B). There are two plausible mechanisms for the observed membrane damage: (1) Oxidative stress-induced lipid peroxidation, and/or (2) direct physical penetration and damage, which were further investigated.

For oxidative stress-induced by GFMs, intracellular ROS generation was examined after GFMs exposure for $96 \mathrm{~h}$. All the three GFMs significantly increased the intracellular ROS level of algal cells, in an order of $\mathrm{rGO}>\mathrm{GO}>\mathrm{MG}$ (Figure 2C). The GFMs-induced oxidative stress in bacteria (Liu et al., 2011) and human cells (Hashemi et al., 2014) was in line with our study. The increase of intracellular ROS generation could be a response to the environmental stress (e.g., GFMs exposure). For GFMs exposure, extracellular ROS spontaneously generated by GFMs themselves could be another source. It is shown that ROS level significantly increased in the 
presence of GO in cell-free algal medium $(p<0.05)$ while $\mathrm{rGO}$ and MG were unable to generate ROS (Figure S11). ROS was reported to be produced during the transformation of GO under simulated sunlight irradiation (Zhao and Jafvert, 2015). Under the simulated sunlight in algal incubator, transformation of GO could also occur (insert image of Figure 1B), which could be the main reason for the detected significant amount of ROS. MDA content can indicate the degree of lipid peroxidation, which was examined after GFMs exposure for $96 \mathrm{~h}(50 \mathrm{mg} / \mathrm{L})$. All the GFMs caused significant lipid peroxidation of membrane (Figure 2C), and the order ( $\mathrm{rGO}>\mathrm{GO}>\mathrm{MG})$ was the same to that of ROS generation, clearly suggesting oxidative stress-induced lipid peroxidation. The oxidation of polyunsaturated fatty acids could lead to the formation of pores and the increase of membrane damage (Van der Paal et al., 2016). However, the order of oxidative stress-induced membrane damage is not exactly correlated to that of membrane damage as examined by flow cytometry $(\mathrm{rGO}>\mathrm{MG}>\mathrm{GO})$ (Figure $2 \mathrm{~A})$, indicating that physical damage could also play an important role in algal membrane damage during the exposure of GFMs (especially rGO and MG).

Physical damage was firstly examined by SEM observation. The edges of rGO and MG directly contacted with algal cells (Figure 3). Particularly, the sheet of MG was clearly penetrated into individual algal cell (Figures 3B,3E). Also, obvious cut was found on the algal surface as indicated by yellow arrow in Figure 3F. We thus concluded that rGO and MG induced direct physical damage to algal cells. There is only one report which showed the direct penetration of MG into human cells (human 
keratinocytes) with sharp edge and corner (Li et al., 2013). Different from human cells, algal cells are more difficult to be directly penetrated due to the protection of cell wall. Our work provides the evidence that graphene materials are able to penetrate into algal cells for the first time. However, we did not find any image that algal cell was directly damaged by GO, which could be explained by the weaker agglomeration and lower contact probability of algal cells with GO than other GFMs. In addition, GO sheets were more flexible than rGO and MG (Shen et al., 2014b), which may be another reason for the less sharp edge.

Detailed process on how GFMs induced membrane damage through physical damage was further investigated. CLSM images showed algal cells (Figure 4A) and in-vitro PC molecules (or their micelles) (Figure S12D) were well dyed by DiI while the three GFMs were unable to be dyed by DiI (Figures S12A-S12C). All the three GFMs could adsorb PC molecules, and the adsorbed PC molecules on GFMs were able to be dyed by DiI as indicated by the red color on the surface of GFMs (Figures S12E-S12G). Therefore, GFMs would be dyed by DiI after they extract phospholipids from membrane of algal cells. After treated with algal cells, the GFMs that directly contacted to algal cells were dyed and observed (Figures 4B-4D). Clearly, GO sheets cannot extract phospholipids in the cell membranes (Figure 4B), which is in agreement with the insignificant heteroaggregation and physical damage of GO. However, rGO (Figure 4C) and MG (Figure 4D) sheets interacted with algal cells were dyed with red color (right columns, indicated with yellow arrows), indicating that $\mathrm{rGO}$ and MG could extract phospholipids from the cell membranes during direct 
contact/penetration with algal cells. Molecular dynamics investigation showed that graphene sheet could destructively extract lipid molecules of membrane double layer through (1) direct penetration when suitable geometric orientation is met, and/or (2) lying flat on the top of the bilayer and creating a patch of upturned phospholipids (Dallavalle et al., 2015). For algal cells, the first manuscript would have a higher probability because of the protection of EPS and cell wall on the external surface of phospholipid membrane. Overall, we can conclude that rGO and MG showed stronger membrane damage than GO. For GO, oxidative stress-induced lipid peroxidation is the dominant mechanism for the observed membrane damage, both oxidative stress and physical penetration/extraction were responsible for the severe membrane damage caused by rGO and MG.

\subsection{Nutrient depletion-induced indirect toxicity}

For all the three GFMs, the growth of algal cells in the supernatant (algal medium after the removal of GFMs) were all significantly decreased in comparison with that in the normal algal medium (modified SE medium), indicating the presence of nutrient depletion. GO, rGO and MG caused $28.7 \%, 20.4 \%$ and $9.4 \%$ of nutrient depletion-induced indirect toxicity (Figure 5A). In addition, the contribution of nutrition depletion to the total toxicity of GO, rGO and $\mathrm{MG}$ was calculated as $53 \%$, $35 \%$, and $27 \%$, respectively. The adsorption of microelements and macroelements by

GFMs was further investigated. For microelements, the concentrations of Fe(III), $\mathrm{Cu}(\mathrm{II})$ and $\mathrm{Zn}(\mathrm{II})$ were not significantly changed after adsorbed onto all the three GFMs while the concentrations of $\mathrm{Mg}^{2+}$ and $\mathrm{Ca}^{2+}$ were significantly decreased after 
adsorption by GO and rGO. Generally, Fe(III) (1.83), Cu(II) (1.90) and $\mathrm{Zn}(\mathrm{II})$ (1.65) with higher electronegativity than $\mathrm{Mg}^{2+}$ (1.31) and $\mathrm{Ca}^{2+}$ (1.01) are expected to have stronger competitive ability on functionalized GFMs (Sitko et al., 2013; Dastgheib et al., 2002). To explain the insignificant adsorption of $\mathrm{Fe}(\mathrm{III}), \mathrm{Cu}(\mathrm{II})$ and $\mathrm{Zn}$ (II) (Figure 5B), the competitive adsorption between $\mathrm{Fe}(\mathrm{III}) / \mathrm{Cu}(\mathrm{II}) / \mathrm{Zn}(\mathrm{II})$ and $\mathrm{Mg}^{2+} / \mathrm{Ca}^{2+}$ on $\mathrm{GO}$ was further investigated (Figure S13). It is shown that $\mathrm{Fe}(\mathrm{III}) / \mathrm{Cu}(\mathrm{II}) / \mathrm{Zn}$ (II) ions could be adsorbed onto $\mathrm{GO}$ at lower $\mathrm{Mg}^{2+} / \mathrm{Ca}^{2+}$ concentrations $(<1 \mathrm{mg} / \mathrm{L})$ while the adsorption was not significant in the presence of higher amount of $\mathrm{Mg}^{2+} / \mathrm{Ca}^{2+}$, which is the case in the algal medium of this study. In addition, $\mathrm{Mn}(\mathrm{II})$ concentration was increased by around 35\% ( $p<0.05)$ after the adsorption by GO (Figure 5B). This is probably because the usage of potassium permanganate during GO production. The increasing Mn concentration from 0.057 to $0.077 \mathrm{mg} / \mathrm{L}$ did not influence algal growth (Figure S14), thus the nutrient depletion-induced toxicity was not related to microelements in algal medium. For macroelements, $\mathrm{K}$ concentration was not changed after the adsorption of the three GFMs (Figure S15A). MG significantly decreased the concentrations of $\mathrm{N}$ (mainly in the form of $\mathrm{NO}_{3}{ }^{-}$) and $\mathrm{P}$ (mainly in the form of $\mathrm{HPO}_{4}{ }^{2-}$ ), probably due to anion- $\pi$ interaction (Zhao et al., 2014a). The depletion of $\mathrm{N}$ and $\mathrm{P}$ could be responsible for the observed algal growth reduction $(p<0.05)$ (Figure 5C). Limited $\mathrm{N}$ and $\mathrm{P}$ could inhibit the synthesis of proteins, lipids and carbohydrates during algal growth (Stehfest et al., 2005). Besides $\mathrm{N}$ and $\mathrm{P}, \mathrm{Mg}$ and $\mathrm{Ca}$ were also highly decreased for GO $(p<0.05)$, which can explain their stronger nutrient depletion-induced toxicity than rGO and MG. In addition, the adsorption of 
$\mathrm{Mg}$ and Ca was positively related to the oxygen contents and zeta potentials of GFMs (Table 1). $\mathrm{Mg}^{2+}$ plays an important role in photosynthesis, and is essential for many enzymatic activities (e.g., protein kinases, RNA plymerase) (Shaul, 2002). $\mathrm{Ca}^{2+}$ is of importance in signal transduction, chlorophyII synthesis and stress-tolerance of algae (Gorain et al., 2013). To further verify the indirect toxicity caused by nutrient depletion, we designed another experiment by increasing the nutrients for 10 times in algal medium. Clearly, growth inhibition induced by all the GFMs was significantly alleviated in 10-fold algal medium $(p<0.05)$ (Figure S15B), further confirming the contribution of nutrient depletion on the toxicity of GFMs.

\section{Conclusions and environmental implications}

In the present work, the $96-\mathrm{h} \mathrm{EC}_{50}$ values of $\mathrm{GO}, \mathrm{rGO}$, and $\mathrm{MG}$ to freshwater (Chlorella pyrenoidosa) were exmained as 37, 34, and $62 \mathrm{mg} / \mathrm{L}$, respectively. For GO, shading effect $(\sim 16 \%)$, oxidative stress-induced membrane damage, and nutrient depletion $(\sim 53 \%)$ were responsible for the observed toxicity. rGO and MG showed no shading effect on algal growth due to their poor dispersibility while nutrient depletion led to $35 \%$ and $27 \%$ of the total toxicity, respectively. Membrane damage induced by both oxidative stress and physical penetration/extraction could be dominant mechanisms for rGO and MG. It is reported that graphene sheets were internalized by human cells (e.g., epithelial cells) and disrupted the cytoskeletal organization of cells (Li et al., 2013). Our finding revealed that despite the protection of cell wall, graphene sheets (i.e., rGO and MG) could still be internalized by algal cells, which indicates the high possibility of GFMs internalization by bacteria and plant cells. In addition, GO 
sheets could be transformed under (simulated) sunlight irradiation. The transformation process is expected to enhance the toxicity of GO through increasing shading effect, surface hydrophobicity, and membrane-damage ability. Therefore, the toxicity of GO in natural aquatic conditions deserves further investigation. Moreover, indirect GFM (also other NPs) toxicity induced by nutrient depletion was neglected in most toxicological studies (Petersen et al., 2014). Our findings suggested that nutrient depletion was of importance for comprehensively assessing the negative effect of GFMs. In most natural environments, the nutrients for algal growth could be less than that in the algal medium. Therefore, the toxicity caused by GFM-induced nutrient depletion in natural environments could be higher. In addition, colloidal behavior of GFMs in natural environments also differs from laboratorial conditions. Thus, the toxicity of GFMs under environmentally relevant conditions (e.g., in the presence of natural organic matter) merits further investigation.

\section{Acknowledgements}

This research was supported by Natural Science Foundation of China (41120134004, 41403092, 41573086), Natural Science Foundation of Shandong (ZR2014DM018), and USDA-NIFA Hatch program (MAS 00475).

\section{Appendix, Supplementary material}

Fifteen figures and one table. This material is available free of charge via the Internet at http://www.sciencedirect.com.

\section{References}

Akhavan, O., 2015. Bacteriorhodopsin as a superior substitute for hydrazine in 
chemical reduction of single-layer graphene oxide sheets. Carbon 81, 158-166.

Akhavan, O., Ghaderi, E., 2010. Toxicity of graphene and graphene oxide nanowalls against bacteria. ACS Nano 4, 5731-5736.

Aruoja, V., Dubourguier, H. C., Kasemets, K., Kahru, A., 2009. Toxicity of nanoparticles of $\mathrm{CuO}, \mathrm{ZnO}$ and $\mathrm{TiO}_{2}$ to microalgae Pseudokirchneriella subcapitata. Sci. Total. Environ. 407, 1461-1468.

Basta, T., Wu, H. J., Morphew, M. K., Lee, J., Ghosh, N., Lai, J., Heumann, J. M., Wang, K., Lee, Y. C., Rees, D. C., Stowell, M. H., 2014. Self-assembled lipid and membrane protein polyhedral nanoparticles. P. Natl. A. Sci. USA. 111, 670-674.

Creighton, M. A., Rangel - Mendez, J. R., Huang, J., Kane, A. B., Hurt, R. H., 2013. Graphene-induced adsorptive and optical artifacts during in vitro toxicology assays. Small 9, 1921-1927.

Dallavalle, M., Calvaresi, M., Bottoni, A., Melle-Franco, M., Zerbetto, F., 2015. Graphene can wreak havoc with cell membranes. ACS Appl. Mater. Inter. 7, 4406-4414.

Dastgheib, S. A., Rockstraw, D. A., 2002. A model for the adsorption of single metal ion solutes in aqueous solution onto activated carbon produced from pecan shells. Carbon 40, 1843-1851.

Fu, C., Liu, T., Li, L., Liu, H., Liang, Q., Meng, X., 2015. Effects of graphene oxide on the development of offspring mice in lactation period. Biomaterials 40, 23-31.

Gorain, P. C., Bagchi, S. K., Mallick, N., 2013. Effects of calcium, magnesium and sodium chloride in enhancing lipid accumulation in two green microalgae. Environ. Technol. 34, 1887-1894.

Hashemi, E., Akhavan, O., Shamsara, M., Rahighi, R., Esfandiar, A., Tayefeh, A. R., 2014. Cyto and genotoxicities of graphene oxide and reduced graphene oxide sheets on spermatozoa. RSC Adv. 4, 27213-27223.

Hu, X., Lu, K., Mu, L., Kang, J., Zhou, Q., 2014. Interactions between graphene oxide and plant cells: Regulation of cell morphology, uptake, organelle damage, 
oxidative effects and metabolic disorders. Carbon 80, 665-676.

Hu, X., Ouyang, S., Mu, L., An, J., Zhou, Q., 2015a. Effects of graphene oxide and oxidized carbon nanotubes on the cellular division, microstructure, uptake, oxidative stress, and metabolic profiles. Environ. Sci. Technol. 49, 10825-10833.

Hu, C., Wang, Q., Zhao, H., Wang, L., Guo, S., Li, X., 2015b. Ecotoxicological effects of graphene oxide on the protozoan Euglena gracilis. Chemosphere 128, 184-190.

Kahru, A., Dubourguier, H.C., 2010. From ecotoxicology to nanoecotoxicology. Toxicology 269, 105-119.

Kang, S., Herzberg, M., Rodrigues, D. F., Elimelech, M., 2008. Antibacterial effects of carbon nanotubes: size does matter! Langmuir 24, 6409-6413.

Li, Y., Yuan, H., von dem Bussche, A., Creighton, M., Hurt, R. H., Kane, A. B., Gao, H., 2013. Graphene microsheets enter cells through spontaneous membrane penetration at edge asperities and corner sites. Proc. Natl. Acad. Sci. USA. 110, 12295-12300.

Liu, S., Zeng, T. H., Hofmann, M., Burcombe, E., Wei, J., Jiang, R., Kong, J., Chen, Y., 2011. Antibacterial activity of graphite, graphite oxide, graphene oxide, and reduced graphene oxide: membrane and oxidative stress. ACS Nano 5, 6971-6980.

Long, Z., Ji, J., Yang, K., Lin, D., Wu, F., 2012. Systematic and quantitative investigation of the mechanism of carbon nanotubes' toxicity toward algae. Environ. Sci. Technol. 46, 8458-8466.

Marcano, D. C., Kosynkin, D. V., Berlin, J. M., Sinitskii, A., Sun, Z., Slesarev, A., Alemany, L. B., Lu, W., Tour, J. M., 2010. Improved synthesis of graphene oxide. ACS Nano 4, 4806-4814.

Novoselov, K. S., Fal, V. I., Colombo, L., Gellert, P. R., Schwab, M. G., Kim, K., 2012. A roadmap for graphene. Nature 490, 192-200.

Petersen, E. J., Henry, T. B., Zhao, J., MacCuspie, R. I., Kirschling, T. L., Dobrovolskaia, M. A., Hackley, V., Xing, B., White, J. C., 2014. Identification 
and avoidance of potential artifacts and misinterpretations in nanomaterial ecotoxicity measurements. Environ. Sci. Technol. 48, 4226-4246.

Quigg, A., Chin, W. C., Chen, C. S., Zhang, S., Jiang, Y., Miao, A. J., Schwehr, K. A., Xu, C., Santschi, P. H., 2013. Direct and indirect toxic effects of engineered nanoparticles on algae: role of natural organic matter. ACS Sustain. Chem. Eng. 1, 686-702.

Schwab, F., Bucheli, T. D., Lukhele, L. P., Magrez, A., Nowack, B., Sigg, L., Knauer, K., 2011. Are carbon nanotube effects on green algae caused by shading and agglomeration? Environ. Sci. Technol. 45, 6136-6144.

Shaul, O., 2002. Magnesium transport and function in plants: the tip of the iceberg. Biometals 15, 307-321.

Shen, Y., Fang, Q., Chen, B., 2014a. Environmental applications of three-dimensional graphene-based macrostructures: adsorption, transformation, and detection. Environ. Sci. Technol. 49, 67-84.

Shen, X., Lin, X., Yousefi, N., Jia, J., Kim, J. K., 2014b. Wrinkling in graphene sheets and graphene oxide papers. Carbon 66, 84-92.

Sitko, R., Turek, E., Zawisza, B., Malicka, E., Talik, E., Heimann, J., Gagor, A., Feist, B., Wrzalik, R., 2013. Adsorption of divalent metal ions from aqueous solutions using graphene oxide. Dalton Trans. 42, 5682-5689.

Slomberg, D. L., Schoenfisch, M. H., 2012. Silica nanoparticle phytotoxicity to Arabidopsis thaliana. Environ. Sci. Technol. 46, 10247-10254.

Stehfest, K., Toepel, J., Wilhelm, C., 2005. The application of micro-FTIR spectroscopy to analyze nutrient stress-related changes in biomass composition of phytoplankton algae. Plant. Physiol. Bioch. 43, 717-726.

Van der Paal, J., Neyts, E. C., Verlackt, C. C., Bogaerts, A., 2016. Effect of lipid peroxidation on membrane permeability of cancer and normal cells subjected to oxidative stress. Chem. Sci. 7, 489-498.

Wang, Z., Li, J., Zhao, J., Xing, B., 2011. Toxicity and internalization of $\mathrm{CuO}$ nanoparticles to prokaryotic alga Microcystis aeruginosa as affected by dissolved 
organic matter. Environ. Sci. Technol. 45, 6032-6040.

Wang, Z., Xie, X., Zhao, J., Liu, X., Feng, W., White, J. C., Xing, B., 2012. Xylem-and phloem-based transport of $\mathrm{CuO}$ nanoparticles in maize (Zea mays L.). Environ. Sci. Technol. 46, 4434-4441.

Zhang, L. Q., Li, J. Y., Yang, K., Liu, J. F., Lin, D. H., 2016. Physicochemical transformation and algal toxicity of engineered nanoparticles in surface water samples. Environ. Pollut. 211, 132-140.

Zhang, S., Jiang, Y., Chen, C. S., Spurgin, J., Schwehr, K. A., Quigg, A., Chin,W., Santschi, P. H., 2012. Aggregation, dissolution, and stability of quantum dots in marine environments: Importance of extracellular polymeric substances. Environ. Sci. Technol. 46, 8764-8772.

Zhang, X., Zhu, F., Chen, L., Zhao, Q., Tao, G., 2013. Removal of ammonia nitrogen from wastewater using an aerobic cathode microbial fuel cell. Bioresource Technol. 146, 161-168.

Zhao, J., Liu, F., Wang, Z., Cao, X., Xing, B., 2015a. Heteroaggregation of graphene oxide with minerals in aqueous phase. Environ. Sci. Technol. 4, 2849-2857.

Zhao, J., Wang, Z., Dai, Y., Xing, B., 2013. Mitigation of CuO nanoparticle-induced bacterial membrane damage by dissolved organic matter. Water Res. 47, 4169-4178.

Zhao, J., Wang, Z., White, J. C., Xing, B., 2014a. Graphene in the aquatic environment: adsorption, dispersion, toxicity and transformation. Environ. Sci. Technol. 48, 9995-10009.

Zhao, J., Wang, Z., Zhao, Q., Xing, B., 2014b. Adsorption of phenanthrene on multilayer graphene as affected by surfactant and exfoliation. Environ. Sci. Technol. 48, 331-339.

Zhao, S., Wang, Q., Zhao, Y., Rui, Q., Wang, D., 2015b. Toxicity and translocation of graphene oxide in Arabidopsis thaliana. Environ. Toxicol. Phar. 39, 145-156.

Zhao, Y., Jafvert, C. T., 2015. Environmental photochemistry of single layered graphene oxide in water. Environ. Sci.: Nano 2, 136-142. 
Zurutuza, A., Marinelli, C., 2014. Challenges and opportunities in graphene commercialization. Nat. Nanotechnol. 9, 730-734. 


\section{Table}

Table 1. Selected physicochemical properties of GFMs.

\begin{tabular}{|c|c|c|c|c|c|c|c|c|c|c|c|}
\hline \multirow{2}{*}{ GFMs } & \multicolumn{5}{|c|}{ Elemental composition $(\%)$} & \multirow{2}{*}{$\mathrm{I}_{\mathrm{D}} / \mathrm{I}_{\mathrm{G}}^{\mathrm{b}}$} & \multirow{2}{*}{$d(\mathrm{~nm})^{\mathrm{c}}$} & \multirow{2}{*}{$\begin{array}{l}\text { BET surface area } \\
\qquad\left(\mathrm{m}^{2} / \mathrm{g}\right)\end{array}$} & \multirow{2}{*}{$\begin{array}{c}\text { Total pore } \\
\text { volume }\left(\mathrm{cm}^{3} / \mathrm{g}\right)\end{array}$} & \multirow{2}{*}{$\begin{array}{l}\text { Zeta potential in } \\
\text { distilled water } \\
(\mathrm{mV})\end{array}$} & \multirow{2}{*}{$\begin{array}{l}\text { Zeta potential } \\
\text { in medium } \\
(\mathrm{mV})\end{array}$} \\
\hline & $\mathrm{C}$ & $\mathrm{O}$ & $\mathrm{H}$ & $\mathrm{S}$ & $\mathrm{N}$ & & & & & & \\
\hline GO & $39.1 \pm 0.4$ & $55.2 \pm 0.5$ & $2.77 \pm 0.09$ & $2.81 \pm 0.04$ & $\mathrm{ND}^{\mathrm{a}}$ & 0.86 & 0.87 & 242 & 0.244 & $-41.9 \pm 1.3$ & $-27.3 \pm 1.3$ \\
\hline $\mathrm{rGO}$ & $62.3 \pm 0.6$ & $30.1 \pm 0.6$ & $2.09 \pm 0.01$ & $0.18 \pm 0.03$ & $5.34 \pm 0.07$ & 1.04 & 0.37 & 624 & 0.490 & $-32.7 \pm 1.3$ & $-24.7 \pm 0.7$ \\
\hline MG & $92.2 \pm 2.3$ & $5.71 \pm 2.2$ & $0.560 \pm 0.050$ & $1.28 \pm 0.10$ & $\mathrm{ND}^{\mathrm{a}}$ & 0.05 & 0.34 & 133 & 0.272 & $-25.6 \pm 1.5$ & $-19.6 \pm 1.1$ \\
\hline
\end{tabular}

${ }^{\mathrm{a}}$ : Not detected; ${ }^{\mathrm{b}}: \mathrm{sp}^{2} / \mathrm{sp}^{3}$ ratio, obtained by Raman spectra ; ${ }^{\mathrm{c}}$ : Interlayer spacing of GFMs, obtained by XRD. 


\section{Figures}
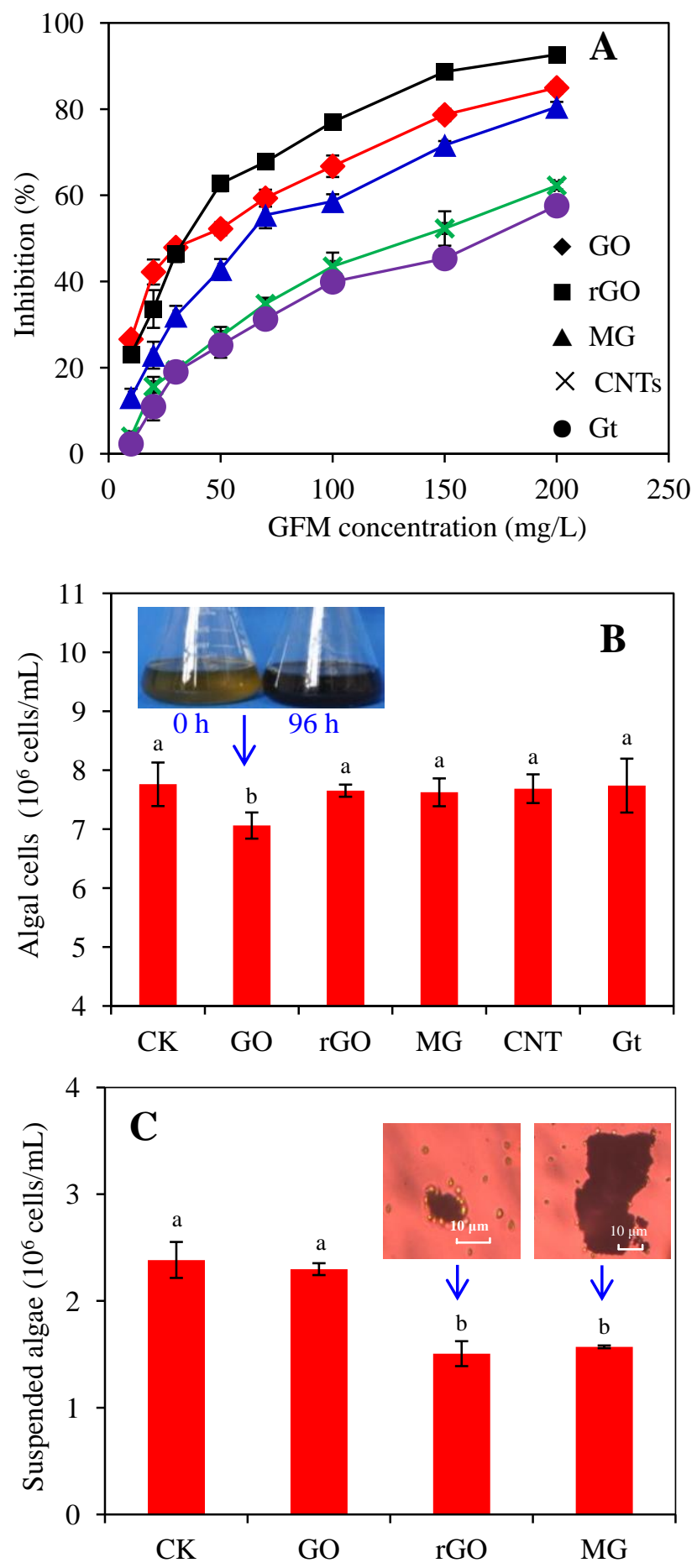

Figure 1. (A) Growth inhibition of algal cells as a function of GFM concentrations after $96 \mathrm{~h}$ exposure. CNTs and graphite (Gt) were also included; (B) Effect of GFMs-induced $(50 \mathrm{mg} / \mathrm{L}, 96 \mathrm{~h}$ ) light shading on the algal growth inhibition; (C) Heteroagglomeration of algal cells with GFMs. Suspended algal cells were counted after GFMs-algae heteroaggregates were settled down for $2 \mathrm{~h}$. In each panel, significant difference among carbon materials is marked with different letters $(p<0.05$, LSD, $n=3$ ). 

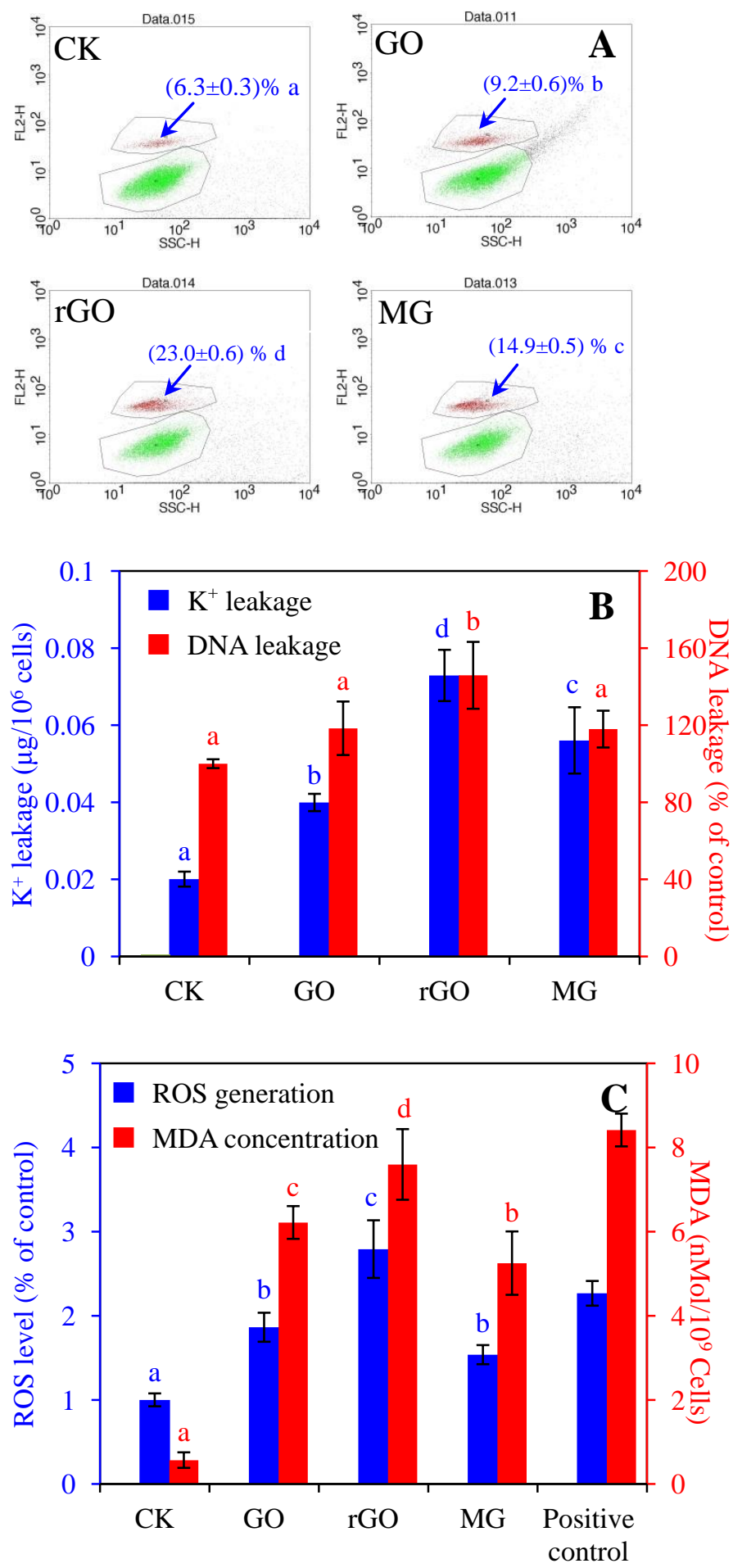

Figure 2. Membrane damage of algal cells after GFMs $(50 \mathrm{mg} / \mathrm{L})$ exposure for $96 \mathrm{~h}$. (A) Flow cytometry results of algal membrane damage after GFMs exposure (green region: intact cells; red region: impaired cells). The values with blue arrows indicate the percentages of membrane-damaged cells of the total cells; (B) Leakage of $\mathrm{K}^{+}$ions (left Y-axis) and DNA (right Y-axis) from GFMs-treated $(50 \mathrm{mg} / \mathrm{L}, 96 \mathrm{~h})$ algal cells; (C) ROS generation (left Y-axis) and MDA content (right Y-axis) of algal cells induced by $50 \mathrm{mg} / \mathrm{L}$ GFMs for $96 \mathrm{~h}$. Hydrogen peroxide was used as the positive control. For all the panels, significant difference among GFMs is marked with 
different letters $(p<0.05, \mathrm{LSD}), \mathrm{n}=3$.
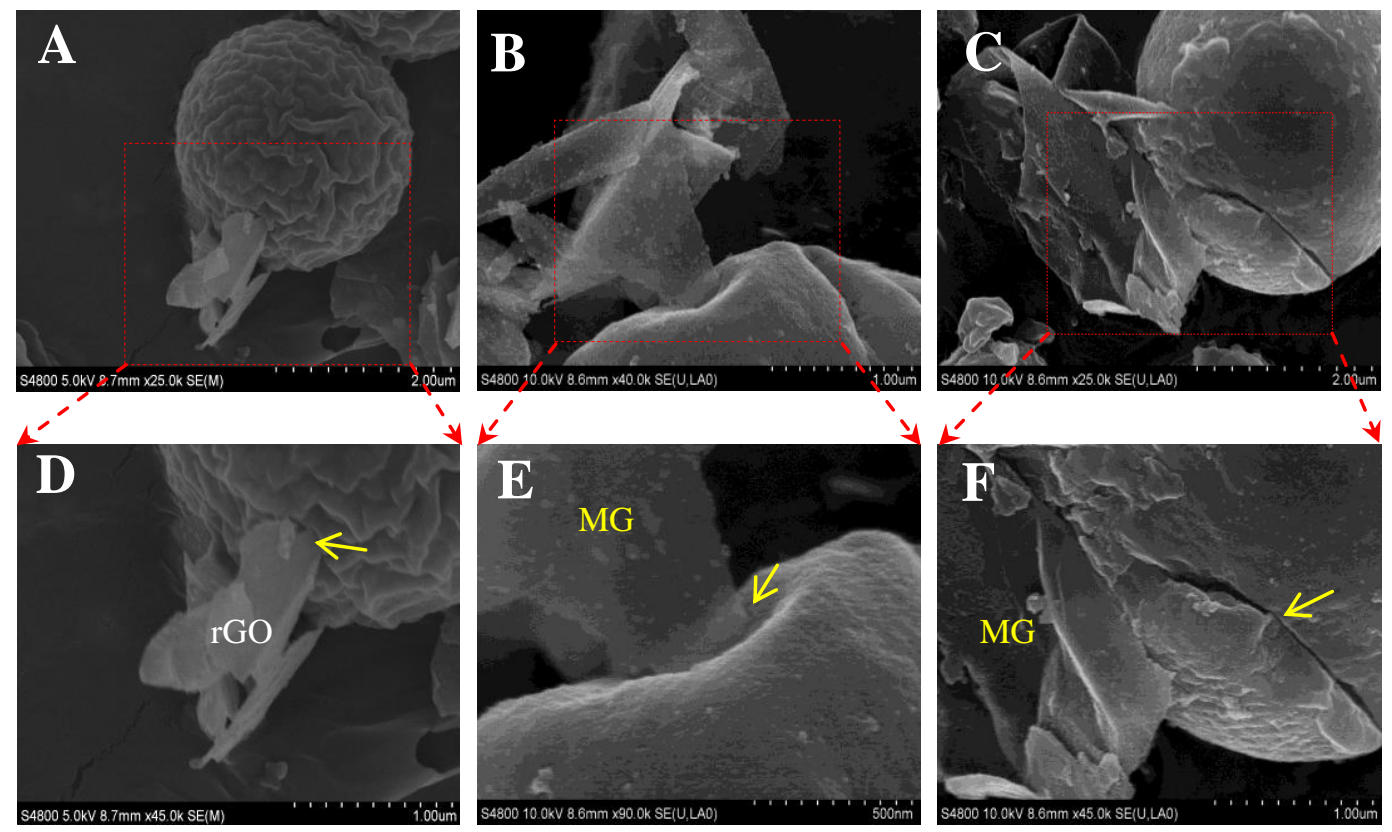

Figure 3. SEM images of algal cells that were physically penetrated by GFMs. (A): algal cells treated by rGO; (B), (C): algal cells treated by MG. The algal cells were exposed to $50 \mathrm{mg} / \mathrm{L}$ GFMs for $96 \mathrm{~h}$ prior to SEM observation. Images D, E, and F are enlarged from the red square frames in images A, B, and C, respectively. Yellow arrows indicate the physical penetration of algal cells. 

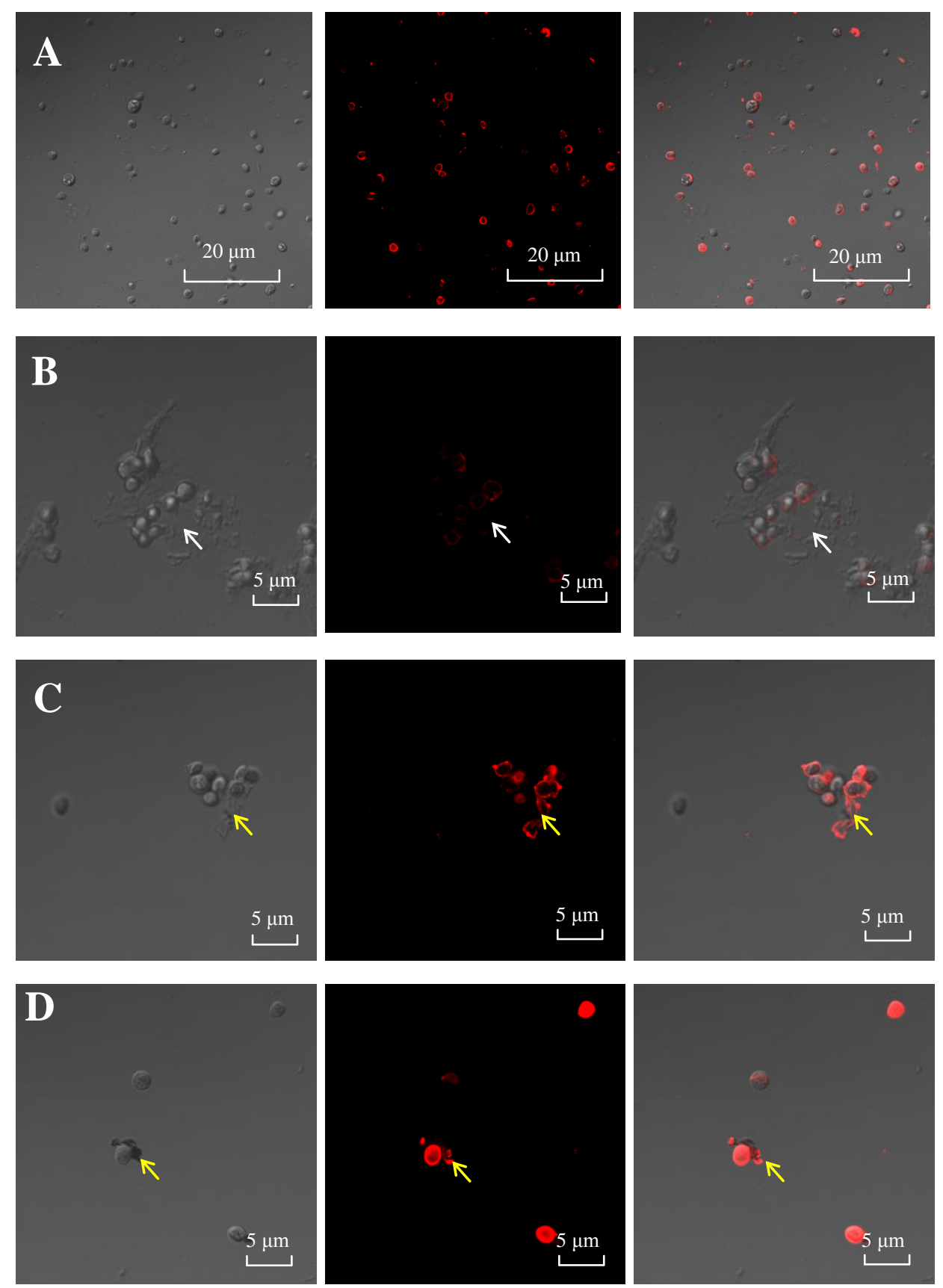

Figure 4. Extraction of lipid molecules from algal membrane of algal cells after GFM (50 $\mathrm{mg} / \mathrm{L}$ ) exposure as examined by confocal laser scanning microscope. (A) Untreated algal cells; (B), (C), and (D): The algal cells exposed to GO, rGO and MG, respectively. In all the treatments, the algal cells were stained with DiI dye before imaging. The left, middle and right columns of the figure are images in dark, light, and overlaid fields. The white arrows in Panel B indicate that GO was not stained by DiI dye. The yellow arrows in Panels $\mathrm{C}$ and $\mathrm{D}$ indicated that $\mathrm{rGO}$ and MG associated with algal cells were stained by DiI dye, suggesting that lipid molecules were adsorbed on the sheets of rGO and MG. 

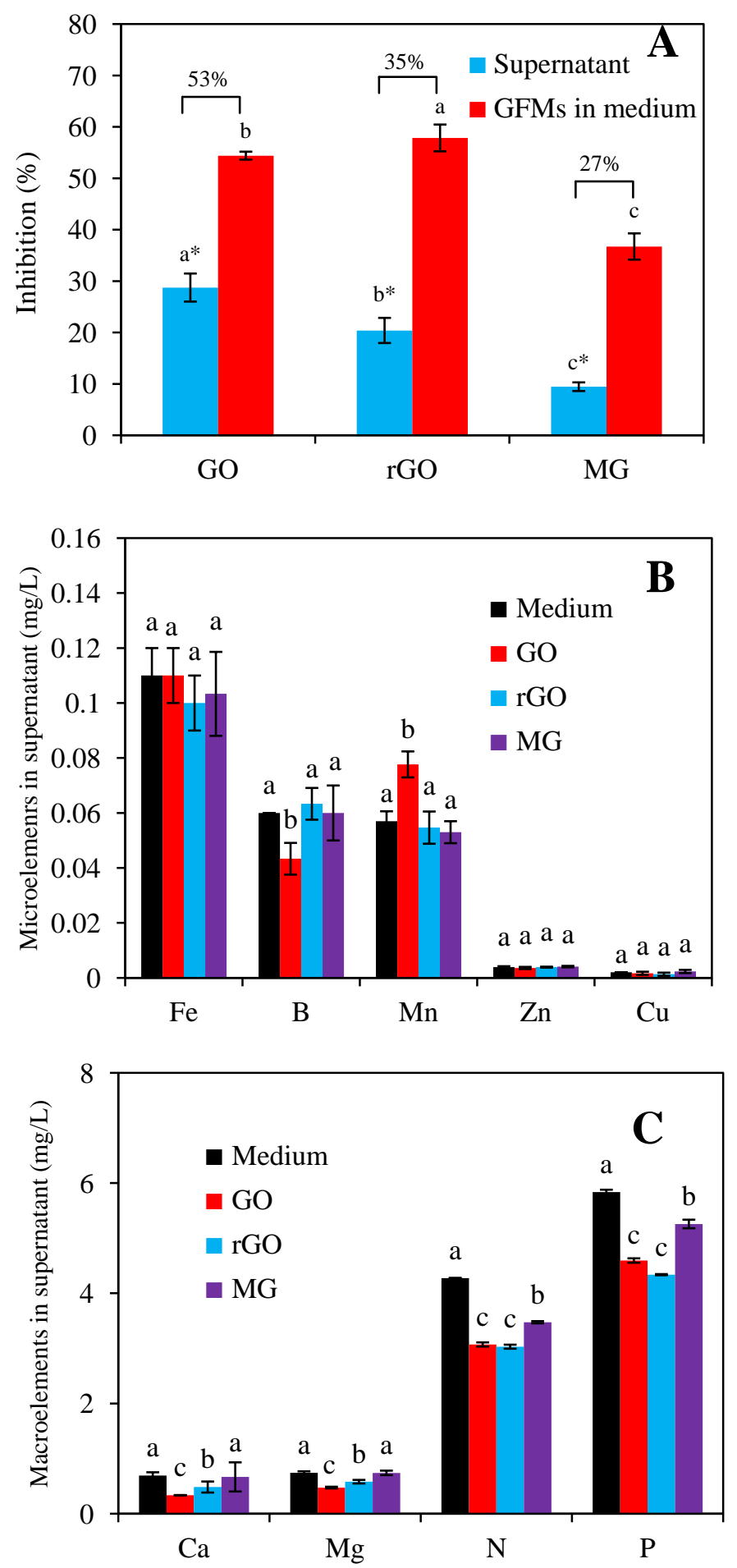

Figure 5. (A) Inhibition of algal growth after exposure to GFMs $(50 \mathrm{mg} / \mathrm{L})$ in medium and their GFM-removed supernatants for $96 \mathrm{~h}$; (B) Concentrations of microelements in supernatants after adsorption; (C) Concentrations of macroelements in supernatants after adsorption. In panel $\mathrm{A}$, different letters represent significant difference among GFMs while "**" indicates significant difference between the inhibition of GFMs in medium and GFM-removed supernatants. In panels B and C, for a given element, different letters represent significant difference among GFMs. 


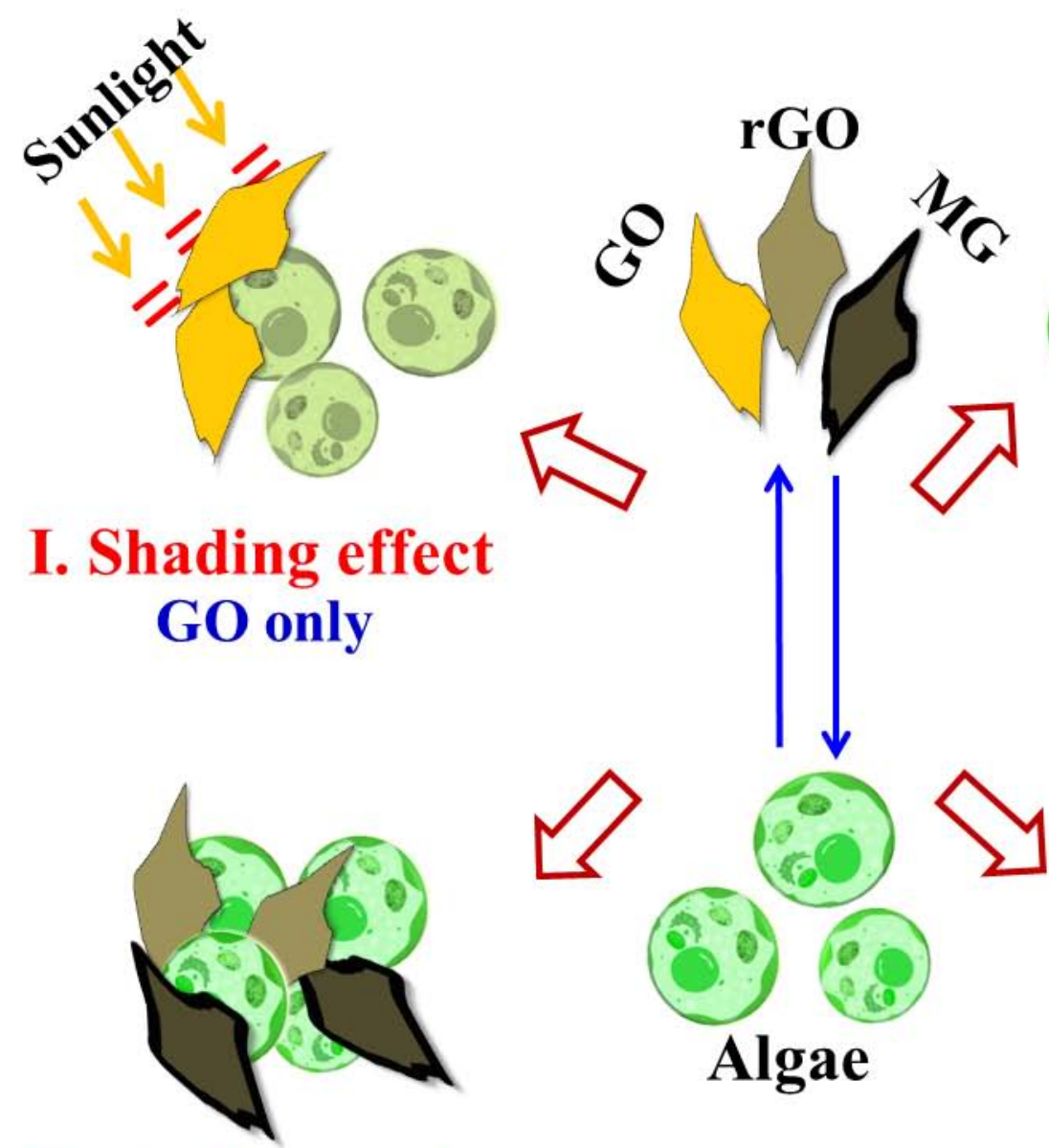

II. Agglomeration $\mathbf{r G O} \approx \mathrm{MG}>\mathbf{G O}$

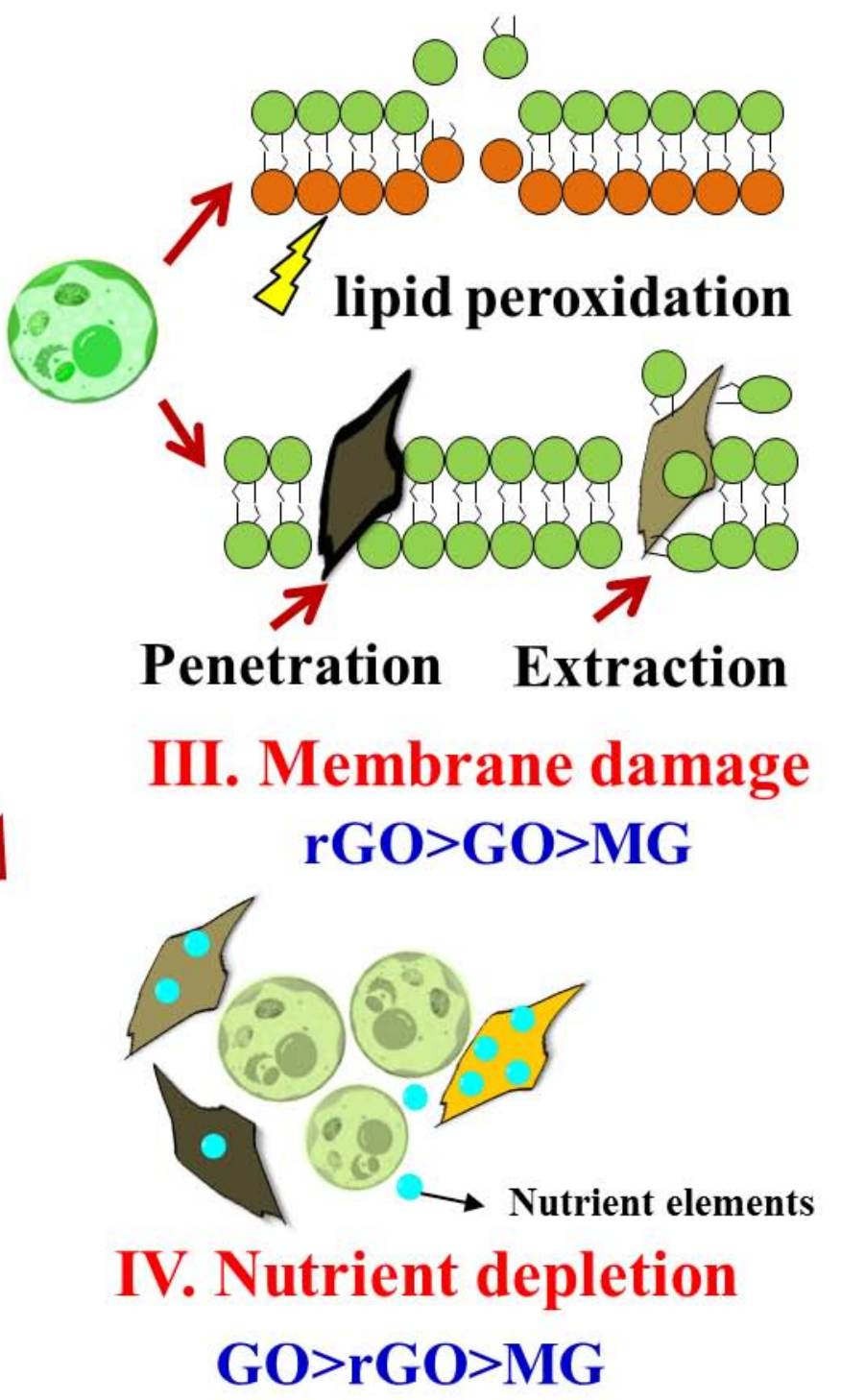

